\title{
Prometeu: Fragmento Dramático, de Goethe
}

Iaci Pinto Souto

\section{Sobre a tradução}

Considero, como uma hipótese, que uma tradução razoável transmite uma obra e não uma língua.

Segundo Antoine Berman, podemos considerar um duplo critério na tradução. O primeiro seria de ordem poética: "A poeticidade de uma tradução reside em que o tradutor realizou um verdadeiro trabalho textual, fez texto, em correspondência mais ou menos estreita com a textualidade do original" ${ }^{\prime 1}$, independentemente dos objetivos do tradutor e das estratégias às quais ele recorreu. $\mathrm{O}$ segundo critério seria de ordem ética: "reside no respeito, ou melhor, num certo respeito do original" 2 .

Na tradução podemos ter como alvo realizar uma versão "elegante" de um texto dado, ou nos aproximarmos o mais perto possível do original, como foi o caso de Nabokov ao traduzir do russo para o inglês o romance de Lermontov Um herói de nosso tempo.

\footnotetext{
“La poéticité d'une traduction réside em ce que le traducteur a rálisé un véritable travail textuel, a fait texte, em correspondance plus ou moins étroite avec la textualité de l'original". BERMAN, Antoine. Pour une critique des traductions: John Donne, Paris, Gallimard, 1995, p. 92.

2 "Réside dans le respect, ou plutôt, dans um certain respect de l'original". BERMAN, Antoine. Pour une critique des traductions: John Donne, Paris, Gallimard, 1995, p. 92.
} 
A esse respeito, Berman cita Chateaubriand, tradutor de Milton, que diz: “É uma tradução literal, em toda a força do termo, que empreendi, uma tradução que uma criança ou um poeta poderão seguir o texto, linha a linha, palavra a palavra, como se tivessem um dicionário aberto sob os olhos" ${ }^{3}$.

A tradução que fiz do fragmento de Goethe pretende ser o mais fiel possível ao texto original, podendo ser comparada e, posteriormente, melhorada.

\section{Sobre a obra}

Prometheus é um fragmento dramático escrito pelo jovem J.W. von Goethe entre 1771 e 1775 e pertencente ao movimento literário alemão chamado Sturm und Drang ${ }^{4}$.

Prometeu, personagem da mitologia grega, emblema da rebelião dos homens contra os deuses, irá, no texto de Goethe, mostrar seu desejo de independência e revolta contra a criação divina.

$\mathrm{O}$ fragmento pode ser dividido em quatro partes.

Na primeira parte, Prometeu deixa claro que a Terra lhe pertence e que Zeus deverá permanecer nos Céus; ele não aceita nenhuma proposta que tenha como meta a divisão de poderes. Isto fica bem nítido quando fala do "meu" e do "teu".

Num segundo momento ele mostra, de forma expressiva, quão insignificantes foram as benesses que os deuses deram aos homens.

Na terceira parte faz um retrospecto de seu passado fundamentando as razões de sua negativa à proposta de divisão de poderes que lhe fora transmitida.

\footnotetext{
“C'est une traduction littérale dans toute la force du terme que j'ai entreprise, une traduction qu'un enfant ou un poète pourront suivre sur le texte, ligne à ligne, mot à mot, comme un dictionnaire ouvert sous les yeux." BERMAN, Antoine. "Chateaubriand traducteur de Milton", in BERMAN Antoine et al., Les Tours de Babel, p. 115, Essais de traduction, Mauvezin, TER., 1985

4 "Tempestade e Ímpeto"
} 
Finalmente, na quarta e última parte, Prometeu mostra a Zeus sua re-criação da humanidade, que irá viver num mundo muito melhor do que aquele que os deuses criaram.

Trata-se de um verdadeiro hino de amor à sua criação colocada em oposição àquela que seria obra divina.

Este texto pode ser considerado como uma grande metáfora. O papel de Zeus pode também ser visto como transferência de uma rebelião contra o Rei, senhor do poder e ao qual o povo está subordinado.

Prometeu dirigir-se-ia, então, ao rei, de forma corajosa, defendendo o direito do povo a uma vida melhor e mais livre.

Assim, em minha leitura, Goethe se serve de Prometeu para expor sua opinião sobre a sociedade alemã da época e a revolta que sente com relação ao poder dos grandes. 
Iaci Pinto Souto. Prometeu: Fragmento Dramático, de Goethe

\section{Prometheus}

\section{Dramatisches Fragment, Johann Wolfgang Von Goethe}

\section{Erst Akt}

\section{Prometheus, Merkur, Epimetheus, Minerva}

Prometheus Ich will nicht, sag es Ihnen!

Und kurz und gut, ich will nicht!

Ihr Wille gegen meinen!

Eins gegen eins.

Mich dünkt es hebt sich!

Merkur Deinem Vater Zeus das bringen?

Deiner Mutter?

Prometheus Was Vater! Mutter!

Weisst du, woher du kommst?

Ich stand, als ich zum erstenmal bemerkte

Die Füsse stehn,

Und reichte, da ich

Diese Hände reichen fühlte,

Und fand die achtend meiner Tritte,

Die du nennst Vater, Mutter.

Merkur Und reichend dir

Der Kindheit note Hülfe.

Prometheus Und dafür hatten sie Gehorsam meiner Kindheit, Den armen Sprössling zu bilden

Dahin, dorthin, nach dem Wind ihrer Grillen.

Merkur Und schützten dich. 
Prometheus Wovor? Vor Gefahren,

Die sie fürchteten.

Haben sie das Herz bewahrt

Vor Schlangen, die es heimlich neidschten?

Diesen Busen gestählt,

$\mathrm{Zu}$ trotzen den Titanen?

Hat nicht mich zum Manne geschmiedet

Die allmächtige Zeit,

Mein Herr un eurer?

Merkur Elender! Deinen Göttern das,

Den Unendlichen?

Prometheus Göttern? Ich bin kein Gott

Und bilde mir so viel ein als einer.

Unendlich? - Allmächtig? -

Was könnt ihr?

Könnt ihr den weiten Raum

Des Himmels und der Erde

Mir ballen in meine Faust?

Vermögt ihr mich zu scheiden

Von mir selbst?

Vermögt ihr mich auszudehnen,

$\mathrm{Zu}$ erweitern zu einer Welt?

Merkur Das Schiksal!

Prometheus Anerkennst du seine Macht?

Ich auch! -

Und geh, ich diene nicht Vasallen!

(Merkur $a b)$

Prometheus 
Iaci Pinto Souto. Prometeu: Fragmento Dramático, de Goethe

(Zu seinen Statuen sich kehrend, die durch den ganzen Hain zerstreut stehen).

Uneersetzliches Augenblick!

Aus eurer Gesellschaft

Gerissen von dem Toren,

Meiner Kinder!

Was es auch ist, das meinen Busen regt -

(Sich einem Mädchen nahend)

Der Busen sollte mir entgegen wallen!

Das Auge spricht schon jetzt!

Sprich, rede, liebe Lippe, mir!

$\mathrm{O}$, könnt ich euch das fühlen geben,

Was ihr seid!

(Epimetheus kommt)

Epimetheus Merkur beklagte sich bitter.

Prometheus Hättest du kein Ohr für Klagen,

Er wär auch ungeklagt zurückgekehrt.

Epimetheus Mein Bruder! Alles, was recht ist!

Der Götter Vorschlag

War diesmal billig.

Sie wollen dir Olympus' Spitze räumen,

Dort sollst du wohnen,

Sollst der Erde hersschen!

Prometheus Ihr Burggraf sein

Und ihren Himmel schützen?-

Mein Vorschlag ist viel billiger:

Sie wollen mit mir teilen, und ich meine,

Dass ich mit ihnen nichts zu teilen habe. 
Das, was ich habe, können sie nicht rauben,

Und was sie haben, mögen sie beschützen.

Hier Mein un Dein,

Und so sind wir geschieden.

Epimetheus Wie vieles ist denn dein?

Prometheus Der Kreis, den meine Wirksamkeit erfüllt!

Nichts drunter und nichts drüber!-

Was haben diese Sterne droben

Für ein Recht an mich,

Dass sie mich begaffen?

Epimetheus Du stehst allein!

Dein Eigensinn verkennt die Wonne,

Wenn die Götter, du,

Die Deinigen und Welt, und Himmel all

Sich all ein innig Ganzes fühlten.

Prometheus Ich kenne das!

Ich bitte, lieber Bruder,

Treib's, wie du kannst, und lass mich!

(Epimetheus ab.)

Prometheus Hier meine Welt, mein All!

Hier fühl ich mich;

Hier alle meine Wünsche

In körperlichen Gestalten.

Meinen Geist so tausendfach

Geteilt und ganz in menen teuern Kindern.

(Minerva kommt) 
Iaci Pinto Souto. Prometeu: Fragmento Dramático, de Goethe

Prometheus Du wagst es, meine Göttin?

Wagest zu deines Vaters Feind zu treiten?

Minerva Ich ehre meinen Vater

Und liebe dich, Prometheus!

Prometheus Und du bist meinem Geist,

War er sich selbst ist;

Sind von Anbeginn

Mir deine Worte Himmelslicht gewesen!

Immer als wenn meine Seele Spräche zu sich selbst,

Sie sich eröffnete

Und mitgeborne Harmonieen

In ihr erklängen aus sich selbst:

Das waren deine Worte.

So war ich selbst nicht selbst,

Und eine Gottheit sprach,

Wenn ich zu rede wähnte,

Und wähnt ich, eine Gottheit spreche,

Sprach ich selbst.

Und so mit dir und mir

So ein, so innig

Ewig meine Liebe dir!

Minerva Und ich dir ewig gegenwärtig!

Prometheus Wie der süsse Dämmerschein

Der weggeschiednen Sonne

Dort heraufschwimmt

Vom finstern Kaukausus

Und meine Seel umgibt mit Wonneruh,

Abwesend auch mir immer gegenwärtig,

So haben meine Kräfte sich entwickelt

Mit jedem Atemzug aus deiner Himmelsluft. 
Und welch ein Recht

Ergeizen sich die stolzen

Bewohner des Olympus

Auf meine Kräfte?

Sie sind mein, und mein ist ihr Gebrauch.

Nicht einen Fusstritt

Für den obersten der Götter mehr!

Für sie? Bin ich für sie?

Minerva So wähnt die Macht.

Prometheus Ich wähne, Göttin, auch

Und bin auchg mächtig.-

Sonst! - Hast du mich nicht oft gesehn

In selbst erwählter Knechtschaft

Die Bürde tragen, die sie

In feierlichem Ernst auf meine Schultern legten?

Hab ich die Arbeit nicht vollender,

Jeder Tagwerk, auf ihr Geheiss,

Weil ich glaubte,

Sie sähen das Vergangne, das Zukünftige

Im Gegenwärtigen,

Und ihre Leitung, ihr Gebot

Sei uranfängliche,

Uneigenützige Weisheit?

Minerva Du dienstest, um Freiheit wert zu sein.

Prometheus Und möcht um vieles nicht

Mit dem Donnervogel tauschen

Und meines Herren Blitze stolz

In Sklavenklauen packen

Was sind sie? Was ich? 
Iaci Pinto Souto. Prometeu: Fragmento Dramático, de Goethe

Minerva Dein Hass ist ungerecht!

Den Göttern fiel zum Lose Dauer

Und Macht und Weisheit und Liebe.

Prometheus Haben sie das all

Doch nicht allein!

Ich daure so wie sie.

Wir alle sind ewig! -

Meine Anfangs erinnr ich mich nicht,

$\mathrm{Zu}$ enden hab ich keinen Beruf

Und seh das Ende nicht.

So bin ich ewig, denn ich bin!

Und Weisheit -

(Sie an den Bildnissen herumführend)

Sieh diese Stirn an!

Hat mein Finger nicht

Sie ausgeprägt?

Und dieses Busens Macht

Drängt sich entgegen

Der allanfallenden Gefahr umher.

(Bleibt bei einer weiblichen Bildsäule stehen)

Und du, Pandora,

Heiliges Gefäss der Gaben alle,

Die ergötzlich sind

Und dem weiten Himmel,

Auf der unendlichen Erde,

Alles, was mich je erquickt von Wonnergefühl,

Was je des Schattens Kühle

Mir Labsal ergossen 
Der Sonne Liebe jemals Frühlingswonne,

Der Meeres laue Welle

Jemals Zärtlichkeit an meinen Busen angeschmiegt,

Und was ich je für reinen Himmelsglanz

Und Seelenruhgenuss geschmeckt -

Das all all - Meine Pandora!

Minerva Jupiter hat dir entboten,

Ihnen allen das Leben zu erteilen,

Wenn du seinem Antrag

Gehör gäbst.

Prometheus Das war das einzige, was mich bedenken machte.

Allein - ich sollte Knecht sein und wir

All erkennen droben die Macht des Donnrers?

Nein! Sie mögen hier gebunden sein

Von ihrer Leblosigkeit,

Sie sind doch frei,

Und ich fühl ihre Freiheit!

Minerva Und sie sollen leben!

Dem Schicksal ist es, nicht den Göttern,

$\mathrm{Zu}$ schenken das Leben und zu nehmen;

Komm, ich leite dich zum Quell des Lebens all,

Den Jupiter uns nicht verschliesst:

Sie sollen leben, und durch dich!

Prometheus Durch dich, o meine Göttin,

Leben, frei sich fühlen,

Leben! - Ihre Freude wird dein Dank sein! 
Iaci Pinto Souto. Prometeu: Fragmento Dramático, de Goethe

\section{Zweiter Akt: Auf Olympus}

\section{Jupiter, Merkur}

Merkur $\quad$ Greuel - Vater Jupiter - Hochverrat
Minerva, deine Tochter,
Steht dem Rebellen bei,
Hat ihm des Lebens Quell eröffnet
Und seinen lettnen Hof,
Seine Welt von Ton
Um ihn belebt.
Gleich uns bewegen sie sich all
Und weben, jauchzen um ihn her,
wie wir um dich.
O, deine Donner, Zeus!

Jupiter Sie sind! Und werden sein!

Und sollen sein!

Über alles, was ist

Unter dem weiten Himmel,

Auf der unendlichen Erde,

Ist mein die Herrschaft.

Das Wurmgeschlecht vermehret

Die Anzahl meiner Knechte.

Wohl ihnen, wenn sie meiner Vatersleitung folgen;

Weh ihnen, wenn sie meinem Fürstenarm

Sich widersetzen.

Merkur Allvater! Du Allgütiger,

Der du die Missetat vergibst Verbrechern,

Sei Liebe dir und Preis

Von aller Erd und Himmel!

$\mathrm{O}$, sende mich, dass ich verkünde 
Denn armen, erdgebornen Volk

Dich, Vater, deine Güte, deine Macht!

Jupiter Noch nicht! In neugeborner Jugendwonne

Wähnt ihre Seele sich göttergleich.

Sie werden dich nicht hören, bis sie dein

Bedürfen. Überlass sie ihrem Leben!

Merkur So weis' als gütig! 
Iaci Pinto Souto. Prometeu: Fragmento Dramático, de Goethe

\section{Tal am fusse des Olympus}

Prometheus Sich nieder, Zeus,

Auf meine Welt: sie lebt!

Ich habe sie geformt nach meinm Bilde,

Ein Geschlecht, das mir gleich sei,

$\mathrm{Zu}$ leiden, weinen, $\mathrm{zu}$ geniessen und $\mathrm{zu}$ freuen sich

Und dein nicht $\mathrm{zu}$ achten

Wie ich!

Man sieht das Menschengeschlecht durch ganze Tal verbreite. Sie sind auf Bäume geklettert, Früchte zu brechen, sie baden sich im Wasser, sie laufen um die Wette auf der Wiese; Mädchen beschäftigen sich, Blumen zu brechen und Kränzgen zu flechten.

Ein Mann mit abgehauenen jungen Bäumen tritt zu Prometheus.

Mann Sieh hier die Bäume,

Wie du sie verlangtest.

Prometheus Wie brachtest du

Sie von dem Boden?

Mann Mit diesen scharfen Steine hab ich sie

Glatt an der Wurzel weggerissen.

Prometheus Erst ab die Äste!

Dann hier rammle diesen

Schief in den Boden hier

Und diesen hier, so gegenüber;

Und oben verbinde sie!-

Dann wieder zwei hier hinten hin

Und oben einen quer darüber.

Nun die Äste herab von oben 
Bis zur Erde,

Verbunden und verschlungen die,

Und Rasen ringsumher,

Die Äste drüber, mehr,

Bis dass kein Sonnenlicht,

Kein Regen, Wind durchdringe.

Hier, lieber Sohn, ein Schutz und eine Hütte!

Mann Dank, teurer Vater, tausend Dank!

Sag, dürfen alle meine Brüder wohnen

In meiner Hütte?

\section{Prometheus Nein!}

Das hast sie dir gabaut und sie ist dein.

Du kannst sie teilen,

Mit wem du willst.

Wer wohnen will, der bau sich selber eine.

(Prometheus $a b$ ) 
Iaci Pinto Souto. Prometeu: Fragmento Dramático, de Goethe

\section{Zwei Männer}

Erster Du sollst kein Stück

Von meinen Ziegen nehmen,

Sie sind mir, mein!

Zweiter Woher?

Erster Ich habe gestern Tag und Nacht

Auf dem Gebirg herumgeklettert,

Und mit saurem Schweiss

Lebendig sie gefangen,

Diese Nacht bewacht,

Sie eingeschlossen hier

Mit Stein und Ästen.

Zweiter Nun gib mir eins!

Ich habe gestern auch eine erlegt,

Am Feuer sie gezeitigt

Und gessen mit meinen Brüdern.

Brauchst du heut mehr als eine?

Wir fangen morgen wieder.

Erster Bleib mir von meinen Schafen!

Zweiter Doch!

(Erster will ihn abhalte, Zweiter gibt ihm einen Stoss, dass er umstürzt, der nimmt eine Ziege und fort)

Erster Gewalt! Weh! Weh!

Prometheus Was gibt's?

(kommt) 
Mann $\quad$ Er raubt mir meine Ziegen! -

Blut rieselt sich von meinem Haupt -

Er schmetterte

Mich wider diesen Stein.

Prometheus Reiss da vom Baume diesen Schwamm

Und leg ihn auf die Wunde!

Mann So - teurer Vater!

Schon is es gestillet.

Prometheus Geh, wasch dein Angesicht.

Mann Und meine Ziege?

Prometheus Lass ihn!

Ist seine Hand wider jedermann,

Wird jedermanns Hand sein wider ihn.

$($ Mann $a b)$

Prometheus Ihr seid nicht ausgeartet, meine Kinder,

Seid arbeitsam und faul,

Und grausam mild,

Freigebig geizig,

Gleichet all euren Schicksalsbrüdern,

Gleichet den Tieren und den Göttern.

(Pandora kommt)

Prometheus Was hast $\mathrm{du}$, meine Tochter,

Wie so bewegt?

Pandora Mein Vater!

Ach, was ich sah, mein Vater,

Was ich fühlte! 
Iaci Pinto Souto. Prometeu: Fragmento Dramático, de Goethe

Prometheus Nun?

Pandora $\quad \mathrm{O}$, meine arme Mira!-

Prometheus Was ist ihr?

Pandora Namenlose Gefühle!

Ich sah sie zu dem Waldgebüsche gehn,

Wo wir so oft die Blumenkränze pflücken;

Ich folgt ihr nach,

Und, ach, wie ich vom Hügel komme,

Seh ich sie, im Tal auf einen Rasen hingesunken.

Zum Glück war Arbar ohngefähr im Wald.

Er hielt sie fest in seinen Armen,

Wollte sie nicht sinken lassen,

Und, ach, sank mit ihr hin.

Ihr schönes Haupt entsank,

Er küsste sie tausendmal

Und hing an ihrem Munde,

Um seinen Geist ihr einzuhauchen.

Mir ward band, ich sprang hinzu und schrie,

Mein Schrei eröffnet ihr die Sinnen.

Arbar liess sie; sie sprang auf,

Und, ach, mit halb gebrochnen Augen

Fiel sie mir um den Hals.

Ihr Busen schlug,

Als wollt er reissen,

Ihre Wangen glühten,

Es lechzt' ihr Mund, und tausend Tränen stürzten.

Ich fühlte wieder ihre Kniee wanken

Und hielt sie, teurer Vater,

Und ihre Küsse, ihre Glut

Hat solch ein neues unbekanntes Gefühl 
Durch meine Adern durchgegossen,

Dass ich verwirrt, bewegt

Und weinend endlich sie liess

Und Wald und Feld,

Zu dir, mein Vater! Sag,

Was ist das alles, was sie erschüttert

Und mich?

Prometheus Der Tod!

Pandora Was ist das?

Prometheus Meine Tochter,

Du hast der Freuden viel genossen.

Pandora Tausendfach! Dir dank ich's all.

Prometheus Pandora, dein Busen schlug

Der kommenden Sonne,

Dem wandlenden Mond entgegen,

Und in den Küsen deiner Gespielen

Genossest du die reinste Seligkeit.

Pandora Unaussprechlich!

Prometheus Was hub im Tanze deinen Körper

Leicht auf vom Boden?

Pandora Freude!

Wie jedes Glied gerührt vom Sang und Spiel

Bewegte, regte sich, ich ganz in Melodie verschwamm.

Prometheus Und alles löst sich endlich auf in Schlaf,

So Freud als Schmerz.

Du hast gefühlt der Sonne Glut, 
Iaci Pinto Souto. Prometeu: Fragmento Dramático, de Goethe

Des Durstes Lechzen,

Deiner Kniee Müdigkeit,

Hast über dein verlornes Schaf geweint,

Und wie geächzt, gezittert,

Da du im Wald den Dorn dir in die Ferse tratst,

Eh ich dich heilte.

Pandora Mancherlei, mein Vater, ist des Lebens Wonn

Und Weh!

Prometheus Und du fühlst an deinem Herzen,

Dass noch der Freuden viel sind,

Noch der Schmerzen, die du nicht kennst.

Pandora Wohl, wohl! - Dies Herze sehnt sich oft

Ach nirgend hin und überall doch hin!

Prometheus Da ist ein Augenblick, der alles erfüllt,

Alles, was wir gesehnt, geträumt, gehofft,

Gefürchtet, meine Beste, - das ist der Tod!

Pandora Der Tod?

Prometheus Wenn aus dem innerst tiefsten Grunde

Du ganz erschütter alles fühlst,

Was Freud und Schmerzen jemals dir ergossen,

Im Sturm dein Herz erschwillt,

In Tränen sich erleichtern will und seine Glut vermehrt,

Und alles klingt an die und bebt und zittert,

Und all die Sinne dir vergehn,

Und du dir zu vergehen scheinst

Und sinkst, und alles um dich her

Versinkt in Nacht, und du, in inner eigenem Gefühle, 
Umfassest eine Welt:

Dann stirb der Mensch.

Pandora O, Vater, lass uns sterben!

(ihn umhalsend)

Prometheus Noch nicht.

Pandora Und nach dem Tod?

Prometheus Wenn alles - Begier und Freud und Schmerz.Im stürmenden Genuss sich aufgelöst,

Dann sich erquickt in Wonneschlaf, -

Dann lebst du auf, aufs jüngste wieder auf,

Aufs neue zu fürchten, zu hoffen und zu begehren! 
Iaci Pinto Souto. Prometeu: Fragmento Dramático, de Goethe

\section{Prometeu}

\section{Fragmento Dramático, Johann Wolfgang Von Goethe}

\section{1o Ato}

\section{Prometeu, Mercúrio, Epimeteu, Minerva}

Prometeu Não quero. Dize a eles!

Em alto e bom som: não quero!

É a vontade deles contra a minha!

Um contra um,

Parece-me claro!

Mercúrio Dizer isto a Zeus, teu pai?

A tua mãe?

Prometeu Que pai! Que mãe!

Sabes de onde vens?

Fiquei de pé pela primeira vez

Quando meus pés

Me sustentaram,

Estendi estas mãos

E elas acompanharam meus passos,

E é isto que chamas Pai, Mãe?

Mercúrio Mas tu não és grato a eles por terem cuidado de ti

Em tua infância?

Prometeu Por isso eles tiveram minha obediência na Infância,

Para construir sua pobre descendência

Aqui, ali, ao vento de seus caprichos. 


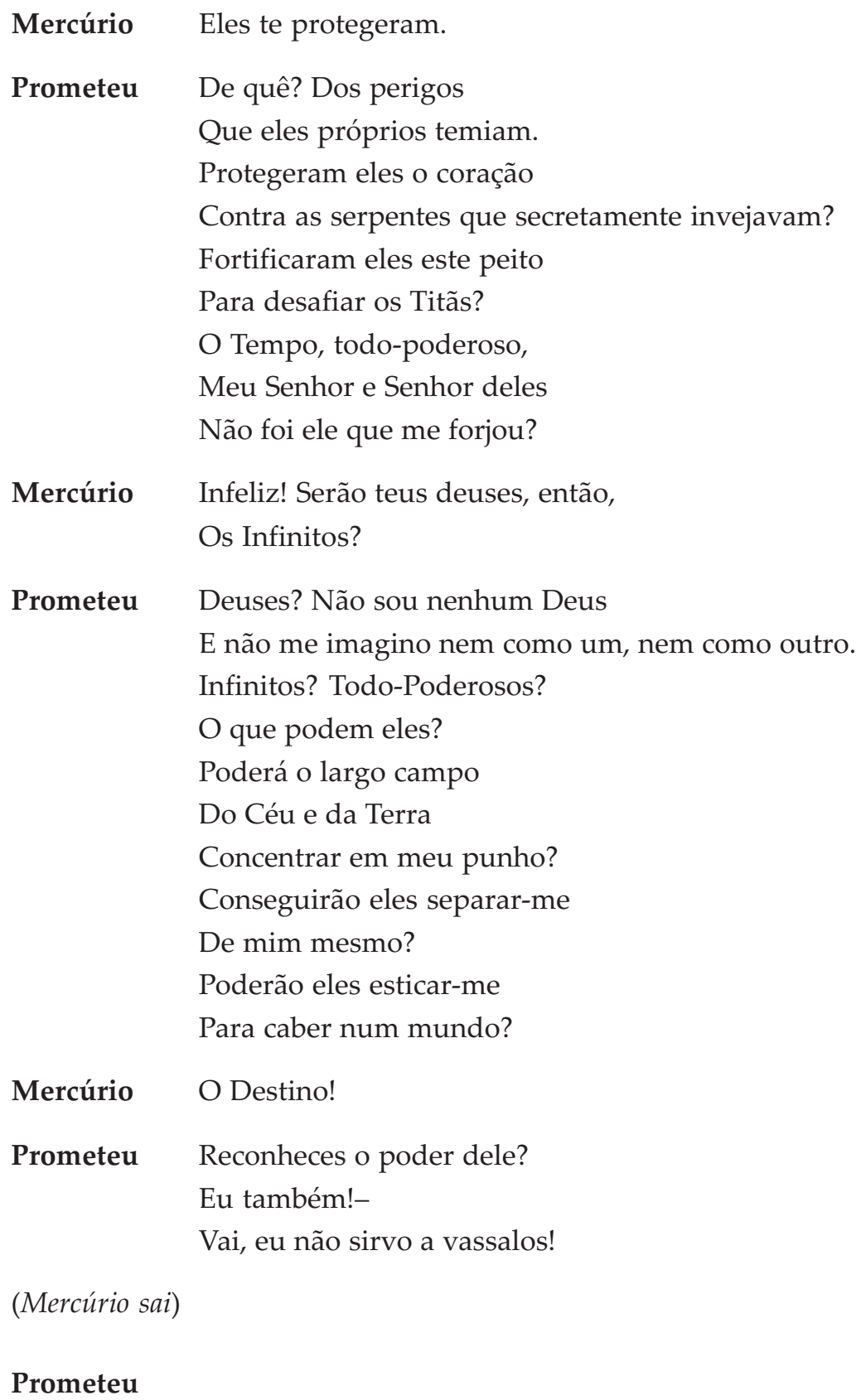


Iaci Pinto Souto. Prometeu: Fragmento Dramático, de Goethe

(virando-se para as estátuas que se encontram espalhadas pelo bosque)

Momento incomparável!

Arrancado aos tolos

Para o convívio de vocês,

Meus filhos!

Que será que está mexendo em meu peito?

(Ele se aproxima de uma jovem)

Meu coração deveria se acelerar diante dela!

Agora o olhar fala!

Falai, conversai comigo, amados lábios!

Ah! Quem me dera transmitir-lhes

$\mathrm{O}$ que eles sabem!

(Epimeteu aproxima-se)

Epimeteu Mercúrio queixa-se amargamente.

Prometeu Se não desses ouvidos a queixas,

Ele teria voltado sem se queixar.

Epimeteu Meu irmão! Tudo o que é de direito!

A proposta dos deuses

Desta vez foi modesta.

Eles querem preparar para ti o cume do Olimpo.

Deves ir morar lá,

E de lá governar a Terra!

Prometeu Ser vassalo deles

E proteger-lhes o céu?

Minha proposta é mais modesta ainda:

Eles querem partilhar comigo, mas penso

Que não tenho nada a dividir com eles.

Mas o que tenho, eles não podem me roubar, 
E o que eles têm, eles mesmos podem cuidar.

Eis aqui o meu e o teu,

E com estas palavras separemo-nos.

Epimeteu O que é teu, então?

Prometeu O círculo onde exerço minha atividade!

Nada abaixo, nem nada acima!-

Teriam estas estrelas lá no alto,

Direito sobre mim

Para me olharem deslumbradas?

Epimeteu Tu estás sozinho!

Tua teimosia julga mal os encantos,

Que viriam da união entre ti,

Os teus e os deuses

Se todos ficassem íntima e integralmente unidos.

Prometeu Conheço bem isso!

Peço-te, querido irmão,

Trata do que quiseres, mas me deixa em paz!

(Epimeteu sai)

Prometeu Aqui é meu mundo e meu universo!

Aqui eu me sinto bem;

Aqui todos os meus desejos

Corporificam-se.

Meu espírito divide-se em mil pedaços

E reflete-se em meus filhos queridos!

(Vem Minerva)

Prometeu Tu ousas, minha Deusa?

Ousas aproximar-te do inimigo de teu Pai? 
Iaci Pinto Souto. Prometeu: Fragmento Dramático, de Goethe

\begin{tabular}{|c|c|}
\hline Minerva & $\begin{array}{l}\text { Eu honro meu Pai, } \\
\text { E te amo, Prometeu! }\end{array}$ \\
\hline Prometeu & $\begin{array}{l}\text { E tu és meu espírito, } \\
\text { Como ele próprio é; } \\
\text { Desde o princípio, tuas palavras, } \\
\text { Tornam-se, para mim, a luz do céu! } \\
\text { Sempre que minha alma fala consigo mesma, } \\
\text { Ela se abre } \\
\text { Numa harmonia secreta } \\
\text { Que ressoa sobre si mesma: } \\
\text { Estas foram tuas palavras. } \\
\text { Então, eu mesmo não sou eu mesmo, } \\
\text { E uma divindade fala } \\
\text { Quando eu imagino falar, } \\
\text { E imagino que uma divindade fala, } \\
\text { Quando eu mesmo estou falando. } \\
\text { Então, tu e eu } \\
\text { Somos um só, tão íntimo } \\
\text { E eterno é meu amor por ti! }\end{array}$ \\
\hline Minerva & E eu estarei sempre presente em ti! \\
\hline Prometeu & $\begin{array}{l}\text { Como o doce crepúsculo } \\
\text { Do sol que se foi } \\
\text { E desapareceu } \\
\text { Lá nas trevas do Cáucaso } \\
\text { Abraça minha alma com encantamento, } \\
\text { A ausência sempre presente para mim, } \\
\text { Então minhas forças aumentam } \\
\text { A cada respiração do ar do teu céu. } \\
\text { E com que direito } \\
\text { Os orgulhosos }\end{array}$ \\
\hline
\end{tabular}


Habitantes do Olimpo

Experimentam suas forças sobre mim?

Elas me pertencem e, também, o uso que delas faço.

Não serão mais um degrau

Para alcançar os deuses lá no alto!

Para eles? Serei eu para eles?

Minerva Assim se imagina o Poder.

Prometeu Eu, também, assim o imagino, Deusa,

Mas, também, eu sou poderoso.

Ou seja! - Não me vistes tu, frequentemente,

Em uma auto-escolhida servidão,

Carregar os fardos que eles

Com solene gravidade, colocaram sobre meus ombros?

Não terminei eu o trabalho diário

Sob a ordem deles,

Porque acreditava

Que eles viam o passado e o futuro

No presente?

E que a conduta e os mandamentos deles

Eram primordiais

E de uma sabedoria gratuita?

Minerva Tu servistes para tornar valiosa a liberdade.

Prometeu Eu não quero trocar nada

Com o pássaro do trovão

E agarrar, orgulhosamente,

Com garras escravas os raios do meu Senhor.

O que são eles? O que sou eu?

Minerva Teu ódio é injusto!

Eternidade, poder, sabedoria e amor

São trunfos dos deuses! 
Iaci Pinto Souto. Prometeu: Fragmento Dramático, de Goethe

Prometeu Eles têm tudo

Mas não só eles!

Eu duro tanto quanto eles.

Nós todos somos eternos!-

Eu nem me lembro do meu começo,

Para terminar não tenho nenhuma profissão

E não vejo o fim.

Então sou eterno, pois existo!

E a sabedoria -

(Ele anda ao redor das estátuas)

Olhe para estas frontes!

Não foram elas modeladas

Com minhas próprias mãos?

E o poder deste peito

Comprime contra si

Os Perigos ocasionais que o rodeiam.

(Permanece imóvel junto a uma estátua de mulher)

E tu, Pandora,

Santo recipiente de todos os presentes,

Que são agradáveis

Sob o imenso céu

E na terra infinita,

Tudo o que me desaltera e me dá um sentimento de felicidade,

O que na sombra fresca,

Sobre mim um bálsamo derrama

$\mathrm{O}$ amor do sol num dia de primavera,

A onda tépida dos mares,

Tudo isso vem aninhar-se, carinhosamente, em meu peito,

E o que eu saboreei como puro brilho do céu 
E tranquilo prazer da alma -

Tudo isto - minha Pandora!

Minerva Júpiter manda te comunicar

Que ele lhes dará vida,

Se deres ouvidos

Ao seu pedido.

Prometeu Isto é a única coisa que me fez refletir.

Entretanto - deverei eu ser escravo e nós todos

Reconheceremos lá em cima o poder dos trovões?

Não! Todas ${ }^{5}$ desejam ficar aqui

Unidas em seu sono,

Assim elas são livres

E eu sinto a liberdade delas!

Minerva E elas devem viver!

É o destino, não os deuses,

Que dá e tira a vida;

Vem, eu vou te levar à fonte de toda a vida

Que Júpiter não fechou para nós;

Elas devem viver, mas através de ti!

Prometeu Através de ti, oh! Minha Deusa,

Viver, sentir-se livre,

Viver! - A alegria delas será o teu agradecimento.

5 Aqui referência às estátuas. 
Iaci Pinto Souto. Prometeu: Fragmento Dramático, de Goethe

\section{2ํㅗㅇ Ato: No Olimpo}

\section{Júpiter, Mercúrio}

Mercúrio Horror - Pai Júpiter - Alta traição!

Minerva, tua filha,

Está do lado do rebelde,

Abriu-lhe a fonte da vida

E no teu pátio,

Teu mundo de argila

Vive nele ao seu redor.

Todos se movem como nós,

Agitam-se, gritam de alegria, aqui, ali,

Como ao redor de ti,

Oh! Teus trovões, Zeus!

Júpiter Eles são! E tornarão a ser!

E devem ser!

Tudo o que se encontra

Sob o vasto céu,

Na terra sem fim,

É comandado por mim.

O gênero dos vermes aumentará

A quantidade dos meus servidores.

Será bom para eles seguirem meu paternal desempenho;

E haverá dor para eles

Se quiserem rebelar-se contra meu braço senhorial.

Mercúrio Pai de todos! Todo feito bondade,

Que perdoa o delito dos criminosos,

Glória a ti

De toda a terra e céu! 
Oh! Mande-me anunciar

Ao pobre povo nascido na terra,

Tua existência, Pai, tua bondade, teu poder!

Júpiter Ainda não! Em sua recém-nascida felicidade

Eles acreditam que suas almas são quase divinas.

Eles não irão te ouvir até que sintam

Necessidade. Deixa-os com suas vidas!

Mercúrio Tão sábio quanto bondoso. 
Iaci Pinto Souto. Prometeu: Fragmento Dramático, de Goethe

\section{Num vale aos pés do Olimpo}

Prometeu Olha para baixo, Zeus,

Para o meu mundo: ele vive!

Eu os formei à minha imagem

Um gênero humano que se assemelha a mim,

Que sofre, chora, goza e se alegra

E que não se importa contigo

Como eu!

Vê-se o gênero humano se espalhar por todo o vale. Eles sobem nas árvores para colher frutos, banham-se nas águas, correm uns atrás dos outros no prado; as moças ocupam-se em colher flores para fazer guirlandas.

Um homem, com novas árvores cortadas, vai até Prometeu.

Homem Olha aqui as árvores

Que pediste.

Prometeu Como tu as arrancaste

Do chão?

Homem Com esta pedra pontiaguda

$\mathrm{Eu}$, facilmente, as arranquei pelas raízes.

Prometeu Primeiro colhe os galhos! -

Depois os crava, profundamente, no chão,

Um aqui, outro ali, um em frente do outro;

E una-os por cima! -

E, novamente, dois aqui, atrás dele.

E, por cima, em transversal.

Agora curva os galhos

De cima para baixo, até a terra;

Liga-os e entrelaça-os, 
E coloque grama em volta.

Põe mais ramos por cima,

Até que nem a luz do sol,

Nem a chuva e nem o vento

Possam penetrar.

Tens então, querido filho, uma proteção e uma cabana!

Homem Obrigado, querido Pai, mil vezes obrigado!

Dize, devo deixar todos os meus irmãos

Morarem na minha cabana?

Prometeu Não!

Tu a construíste e ela é tua.

Podes dividi-la com quem quiseres.

Mas quem quiser morar, deve construir

Uma para si próprio;

(Prometeu sai) 
Iaci Pinto Souto. Prometeu: Fragmento Dramático, de Goethe

\section{Dois Homens}

$\mathbf{1}^{\mathbf{0}}$ Homem Tu não deves pegar

Nenhuma de minhas cabras

Elas são minhas!

$2^{\mathbf{o}}$ Homem De onde?

$1^{\text {o }}$ Homem Ontem, dia e noite

Escalei a montanha ao redor,

E com suor amargo,

Aprisionei-as vivas.

Esta noite eu as vigiei

E prendi-as aqui

Com pedras e galhos.

2ํㅜ Homem Mas dê-me uma!

Ontem, eu também abati uma,

Cozinhei-a

E a comi com meus irmãos.

Precisas tu, hoje, mais do que uma?

Nós pegaremos outra amanhã.

1ํㅡㄴ Fique longe dos meus carneiros!

2º Homem Não!

(O primeiro homem quer se afastar, mas o segundo dá-lhe um soco, derrubando-o; pega uma cabra e foge)

1o Homem Violência. Ai! Ai!

Prometeu O que houve?

(aproximando-se) 


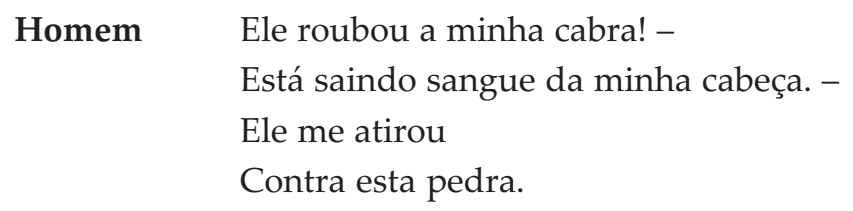

Prometeu Retira da árvore aquela esponja

E coloca-a sobre a ferida!

Homem Assim - caro Pai!

Logo o sangue já está parando.

Prometeu Vá, e lava o rosto.

Homem E minha cabra?

Prometeu Deixe-a!

Se alguém levantar a mão contra alguém,

A mão de alguém também se levantará contra ele.

(O homem sai)

Prometeu Vocês não vão degenerar, meus filhos,

Sejam trabalhadores e preguiçosos,

Clementes, cruéis

Avaramente generosos,

Assemelhem-se a todos os seus irmãos do mesmo destino

Assemelhem-se a animais e a deuses. ${ }^{6}$

(Pandora aproxima-se)

Prometeu O que tens, minha filha,

Para agitar-se assim?

Pandora Meu Pai!

Oh! Que vi eu, meu Pai,

O que senti eu!

- Emprego de "vocês" em lugar de "vós" para tornar o texto mais leve em português. 
Iaci Pinto Souto. Prometeu: Fragmento Dramático, de Goethe

Prometeu O quê?

Pandora Oh, minha pobre Mira! -

Prometeu O que houve com ela?

Pandora Sentimentos inomináveis!

Eu a vi andando por uma floresta de arbustos,

Onde nós colhíamos flores para as guirlandas;

Eu a segui,

Então, ai, quando cheguei à colina,

Eu a vi, no vale, desfalecer sobre a grama.

Felizmente, Arbar, o temível, estava perto do bosque.

Ele a tomou em seus braços

Não querendo deixá-la cair,

E, então, jogou-se sobre ela.

A bela cabeça dela tombou para trás,

Ele a beijou mil vezes

E colou seus lábios aos dela

Para insuflar-lhe o espírito.

Eu fiquei com medo, pulei para lá e gritei,

Meu grito fê-la recobrar os sentidos.

Arbar deixou-a; ela se levantou

E, então, com olhos semidesfalecidos,

Pendurou-se em meu pescoço.

O coração dela batia

Como se fosse arrebentar,

Suas faces estavam coradas,

Sua boca parecia sedenta e mil lágrimas caíram

Eu senti que, novamente, seus joelhos vacilaram

Então, segurei-a, caro Pai,

E os beijos dela, seu ardor,

Tinham como um novo sentimento desconhecido 


\author{
Correram pelas minhas veias, \\ De tal forma que eu me perturbei e me agitei \\ E finalmente deixei-a \\ E corri pelos bosques e pelos campos \\ Até chegar a ti, meu Pai! Diga-me, \\ O que é tudo isso que sacudiu a ela \\ E também a mim?
}
Prometeu A morte!
Pandora O que é isto?
Prometeu Minha filha,
Tu gozaste muitas alegrias.
Pandora De mil maneiras! E eu te agradeço por tudo.
Prometeu Pandora, teu peito bateu
De encontro ao sol vindouro,
De encontro à ambulante Lua,
E nos beijos dos teus companheiros
Gozaste da alegria suprema.

Pandora Alegria inexprimível!

Prometeu O que, na dança, elevou teu corpo

Tornando-o leve sobre o chão?

Pandora A alegria!

Cada um de meus membros em cantos e jogos

Moveu-se, e eu me senti diluir toda em melodia.

Prometeu E tudo se desfez, finalmente, no sono,

Tanto alegrias quanto dor.

Sentiste o ardor do sol, 
Iaci Pinto Souto. Prometeu: Fragmento Dramático, de Goethe

Sofreste de sede, saudade

Teus joelhos se fatigaram,

Choraste pelo carneiro perdido,

Sofreste e gemeste

Quando, no bosque, o espinho penetrou no teu calcanhar:

Antes que eu te curasse.

Pandora Por vezes, meu Pai, a vida é delícia

E dor!

Prometeu E tu sentiste em teu coração,

Que quanto mais há alegrias,

Mais dores que tu ignoras.

Pandora Sim! Sim! - Este coração anseia frequentemente,

Por nenhum lugar e por todos os lugares!

Prometeu Há um momento que tudo preenche

Tudo por que nós ansiamos, sonhamos, desejamos,

E tememos, querida filha, - isto é a Morte!

Pandora A morte?

Prometeu Quando do interior e mais profundo íntimo

Tu te sentires totalmente transtornada,

E jamais alegria e dor se derramem sobre ti

Em tormenta teu coração expandindo ${ }^{7}$

E quiser aliviar-se em lágrimas e aumentar seu ardor,

E tudo ressoar em ti e tu vibrares e tremeres,

E todos os teus sentidos te abandonarem

7 Erschwellen - aumentar, inchar. Traduzida por "expandir" por considerar mais adequada ao português. 
E tiveres a impressão de desmaiar

E tudo em ti se perder em noite,

E tu - com um sentimento profundo e íntimo -

Sentires como se contivesses um mundo:

Verás que assim morre o Homem.

Pandora Oh, Pai, então nos deixe morrer!

(pendurando-se em seu pescoço)

Prometeu Ainda não.

Pandora E depois da morte?

Prometeu Quando tudo - desejo, alegria e dor -

Em tempestuoso gozo desintegrar-se,

Então recriar-se-á um sono de felicidade,

E aí tu renascerás, novamente jovem,

Para, novamente, temer, esperar e desejar! 